\title{
Air-surface exchange measurements of gaseous elemental mercury over naturally enriched and background terrestrial landscapes in Australia
}

\author{
G. C. Edwards and D. A. Howard \\ Department of Environment and Geography, Macquarie University, North Ryde, NSW, 2109, Australia
}

Correspondence to: G. C. Edwards (grant.edwards@mq.edu.au)

Received: 28 August 2012 - Published in Atmos. Chem. Phys. Discuss.: 24 October 2012

Revised: 2 May 2013 - Accepted: 2 May 2013 - Published: 27 May 2013

\begin{abstract}
This paper presents the first gaseous elemental mercury (GEM) air-surface exchange measurements obtained over naturally enriched and background $\left(<0.1 \mu \mathrm{g} \mathrm{g}^{-1} \mathrm{Hg}\right)$ terrestrial landscapes in Australia. Two pilot field studies were carried out during the Australian autumn and winter periods at a copper-gold-cobalt-arsenicmercury mineral field near Pulganbar, NSW. GEM fluxes using a dynamic flux chamber approach were measured, along with controlling environmental parameters over three naturally enriched and three background substrates. The enriched sites results showed net emission to the atmosphere and a strong correlation between flux and substrate $\mathrm{Hg}$ concentration, with average fluxes ranging from $14 \pm 1 \mathrm{ng} \mathrm{m}^{-2} \mathrm{~h}^{-1}$ to $113 \pm 6 \mathrm{ng} \mathrm{m}^{-2} \mathrm{~h}^{-1}$. Measurements at background sites showed both emission and deposition. The average $\mathrm{Hg}$ flux from all background sites showed an overall net emission of $0.36 \pm 0.06 \mathrm{ng} \mathrm{m}^{-2} \mathrm{~h}^{-1}$. Fluxes show strong relationships with temperature, radiation, and substrate parameters. A compensation point of 2.48 , representative of bare soils was determined. For periods of deposition, dry deposition velocities ranged from $0.00025 \mathrm{~cm} \mathrm{~s}^{-1}$ to $0.0083 \mathrm{~cm} \mathrm{~s}^{-1}$ with an average of $0.0041 \pm 0.00018 \mathrm{~cm} \mathrm{~s}^{-1}$, representing bare soil, nighttime conditions. Comparison of the Australian data to North American data suggests the need for Australianspecific mercury air-surface exchange data representative of Australia's unique climatic conditions, vegetation types, land use patterns and soils.
\end{abstract}

\section{Introduction}

Mercury is a global pollutant; it is ubiquitous in the environment and is a threat to the health of humans and ecosystems. In general there is a paucity of high-quality mercury air-surface exchange data sets (Zhang et al., 2009, 2012) and, in particular, a lack of representative data on the cycling of natural emissions of mercury to and from the atmosphere (Pirrone et al., 2010; Selin, 2009; Gustin et al., 2008; Schroeder et al., 2005). The atmosphere is the central pathway for distribution of this neurotoxicant globally. Natural sources of mercury include wildfires, soil, vegetation, and geologically enriched terrain, volcanic, oceanic and fresh water (Gustin, 2003). Reliable and representative air-surface exchange measurements of natural sources of mercury are needed to put into perspective the long-term human and ecological risks from anthropogenic activity associated with this volatile metal. These data, along with concurrent measurements of controlling environmental parameters, are required to improve our understanding of the biogeochemical cycling of mercury, thereby improving model empiricism and better constraining estimates of natural sources inventories (Pirrone et al., 2010).

Recent efforts to establish a mercury natural sources inventory for Australia by Nelson et al. (2009) revealed there are no data on the air-surface exchange of atmospheric mercury from natural sources over Australian environs. Moreover, there is an overall dearth of flux data on natural sources and sinks of atmospheric mercury in the Southern Hemisphere (Edwards and Howard, 2011). As such, estimates of the Australian natural sources inventory are reliant on emission factors and empiricism based on North American and 
European data sets, leading to high uncertainty in the estimates. Estimates for mercury emissions in Australia, not including ocean, range from 117 to 567 tonnes per year (Nelson et al., 2004), and more recently 148 tonnes per year, by Cope et al. (2009).

Australia is the second driest continent on earth after Antarctica and has a diverse range of climate zones (i.e. equatorial, tropical, subtropical, desert, grassland and temperate, based on Koppen classification). Most of Australia is covered by arid and semi-arid climates, being warm to hot with the exception of the alpine area in the southeast which has seasonal snow. In addition to wide seasonal variations, Australian climates experience long-term variations under the influence of El Niño (BOM, 2008). Australian climatic conditions are unique from North America and Europe, as are its vegetation types, land use patterns and soils. Australian-specific mercury air-surface exchange data are therefore needed to better constrain natural sources inventories. Estimates of anthropogenic emissions for Australia suggest they account for approximately $7 \%$ of the total burden to the atmosphere (Nelson et al., 2009). With substantially less anthropogenic emissions to the atmosphere, coupled with background atmospheric mercury concentrations constant over hemispheric scales and approximately $25 \%$ less in the Southern Hemisphere (SH) than the Northern Hemisphere (NH) (Pirrone et al., 2010), Australia presents a unique opportunity to study and address uncertainties in the global biogeochemical cycle of mercury associated with land-atmosphere cycling.

To address the need for Australian-specific data on natural mercury emissions, an extensive measurement program has been proposed to collect mercury air-surface exchange data and environmental correlates over natural sources in Australian landscapes. Two pilot studies were carried out during April and June (i.e. Australian autumn and winter) 2011 over mercuriferous and background substrates near a copper-gold-cobalt-arsenic-mercury mineral field at Pulganbar, NSW. During these studies, gaseous elemental mercury (GEM) air-surface exchange and environmental measurements were made.

This paper presents the first Australian-specific GEM airsurface exchange measurements along with controlling climatic and substrate variables. The results are compared to results from similar studies carried out by the first author in North America. This research goes towards advancing our understanding of mercury cycling in Australian environments.

\section{Methodology}

\subsection{Site selection and description}

According to Rytuba (2003), mercuriferous mineral enrichment is concentrated in 26 mercury mineral belts globally.
One of these mercury mineral belts runs along the eastern coast of Australia and extends into Tasmania (Rytuba, 2003). Generally, mercury mineral belts are concentrated in geological settings associated with previously or currently active plate tectonic margins, volcanism or geothermal activity (Gustin et al., 2006). In addition to this primary mercury mineralization, Australia has many pockets of volcanogenic massive sulphide (VMS) and sedimentary exhalitive (sedex) mineral deposits which can contain up to 1200 ppm mercury (Rytuba, 2005).

The focus of the investigation for a site to carry out the pilot studies was on the primary mercury mineralization zones. Seven potential sites were identified through information collected from the Australian Bureau of Statistics (ABS, 1912). The Year Book Australia (1912) reported cinnabar had been mined or prospected around the Bingara, Clarence River and Pulganbar areas of NSW, Kilkivan and Black Snake in the Wide Bay district of Queensland, the Jamieson area of Victoria and in the vicinity of Willunga in South Australia (Fig. 1a).

Pulganbar, NSW $\left(29^{\circ} 28^{\prime} \mathrm{S}\right.$ and $152^{\circ} 40^{\prime}$ E, elevation $81 \mathrm{~m}$; see Fig. 1) was selected for the pilot studies, as a known cinnabar deposit in the vicinity was mined from 1914 to 1924. It was reported that 2000 tons of mercury ore were mined and treated from this deposit (NSW OEH, 2003). A reconnaissance survey of the area identified a natural, undisturbed measurement site approximately $1 \mathrm{~km}$ southeast of the old mine and smelter location, as shown in the mineralized zones in the sediment-acid volcanic sequence (Fig. 1c). The undisturbed area selected for the flux measurements was characterized by slightly rolling terrain and was sparsely treed with eucalypt (Fig. 1b). The forest floor was principally bare soil with scant leaf litter and sparse patches of grassy understory a few $\mathrm{cm}$ in height. The eucalypt stand, depending on the time of day, partially shaded the flux measurement sites.

Exploration activity at the site carried out approximately a decade earlier (CWGOLD, 2008) had left excavated mineralized material from the test pits and drill holes on the surface. This mineralized material provided the basis for the enriched substrate measurements. In addition, several sites were selected nearby on the undisturbed overburden to facilitate background measurements.

The site is rural, located on a cattle station far from any local anthropogenic sources other than potentially from the tailings of the old mine and smelter site. Two pilot field studies were carried out at the Pulganbar site, during the Australian autumn (April) and winter (June).

\subsection{Dynamic flux chamber method}

The dynamic flux method used aligns with current common practice (Eckley et al., 2010; Carpi et al., 2007; Zhang et al., 2002; Gillis and Miller, 2000; Edwards et al., 2001) and is described in detail in Rasmussen et al. (2005). The 

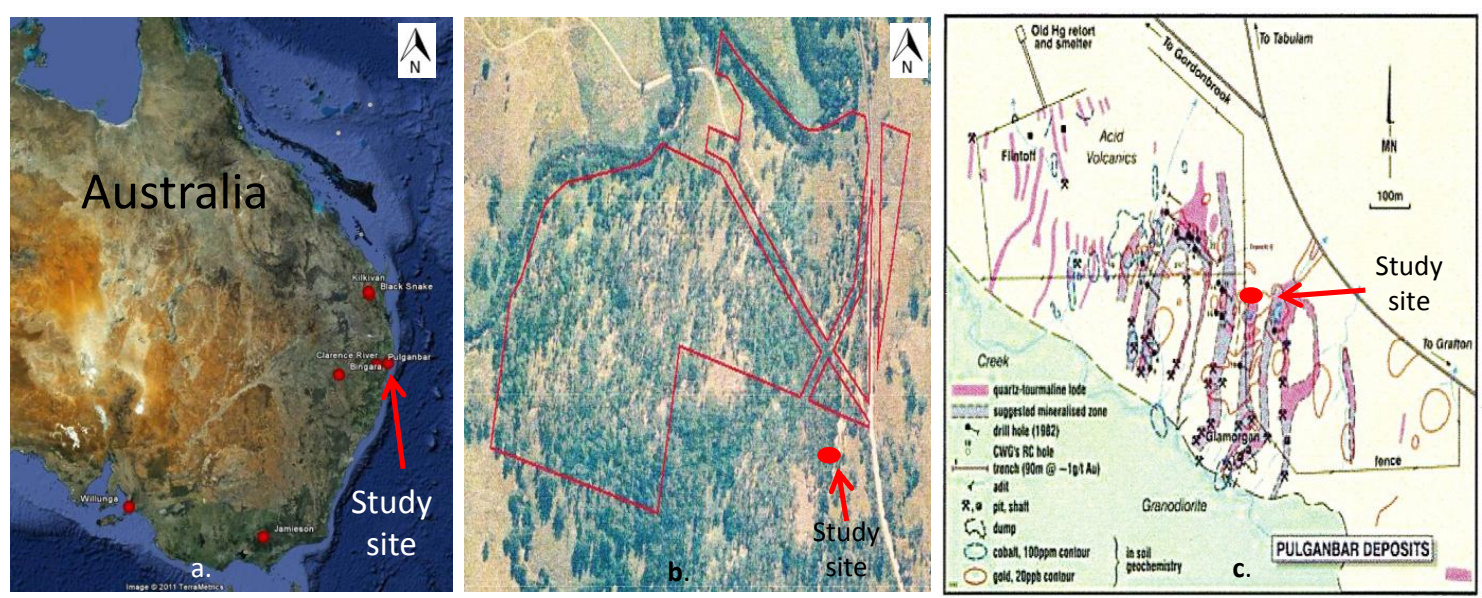

Fig. 1. Locations of pilot studies at Pulganbar, NSW. (a) Image from Google Earth maps 2010. (b) Aerial photograph of Pulganbar site (Central West Gold, 2008). (c) Pulganbar deposits (Central West Gold, 2008).

semi-cylindrical chamber is low profile (i.e., $0.1 \mathrm{~m}$ ) and has a footprint of $0.1 \mathrm{~m}^{2}$, and a volume of $0.008 \mathrm{~m}^{3}$. A vacuum pump and mass flow controller facilitated adjustment of the hydraulic retention time. A unique aspect of the chamber design used is its construction of quartz glass to allow the full transmission of UV-B. Spectroradiograph testing carried out by Kemp (2001) of materials common in mercury flux chamber construction found quartz glass to transmit the full spectrum of incoming solar radiation, in particular UV-B (Fig. 2). Quartz glass is easy to clean and has low sorption characteristics, resulting in low blank qualities.

Based on mass balance, steady state, and well mixed assumptions, the dynamic chamber flux is calculated using the following equation:

$F=Q\left(C_{\text {out }}-C_{\text {in }}\right) / A$,

where $F$ is the mean flux of GEM $\left(\mathrm{ng} \mathrm{m}^{-2} \mathrm{~h}^{-1}\right), C_{\text {out }}$ is the mean GEM leaving the chamber $\left(\mathrm{ng} \mathrm{m}^{-3}\right), C_{\text {in }}$ is the mean GEM concentration entering the chamber $\left(\mathrm{ng} \mathrm{m}^{-3}\right), Q$ is the volumetric flow rate $\left(\mathrm{m}^{3} \mathrm{~h}^{-1}\right)$ and $A$ is the chamber aerial footprint $\left(\mathrm{m}^{2}\right)$.

A Tekran 2537A Total Gaseous Mercury Analyser, coupled with a Tekran 1110 synchronized two port sampling system was used to measure GEM in the inlet and outlet air streams. The sampling protocol was designed to eliminate any mercury analyzer cartridge bias and switching/delay effects in the mean concentration difference calculation.

\subsection{Experimental design and environmental measurements}

Dynamic flux chamber measurements of gaseous elemental mercury fluxes were undertaken over enriched substrates and background soils at the Pulganbar site. GEM fluxes were measured continuously at each chamber location, except for short periods for blank measurement, calibration checking and servicing the instrumentation. A short period at the beginning of the June study was dedicated to ambient concentration measurement.

Flux measurements were carried out over six locations during the April (autumn) and June (winter) field campaigns, three mercuriferous and three background, providing a basis for representative sampling and assessing variability. A number of meteorological and environmental parameters were measured simultaneously during the monitoring periods, using a suite of field-portable instruments described below. A small caravan housed the Tekran 2537A and computer. The site was powered by a gasoline-fuelled, $6 \mathrm{KVA}$ portable generator ( $\mathrm{Hg}$ emission from exhaust, at $1.18 \mathrm{ng} \mathrm{m}^{-3}$, was not significantly different from ambient $\mathrm{Hg}$ concentration measured on site).

\subsubsection{Environmental variables}

Ambient measurements of air temperature, humidity, barometric pressure, wind speed and wind direction were obtained at screen height (i.e. $2 \mathrm{~m}$ ) using a WXT520 mini weather station (Vaisala Pty Ltd.). Nearby, ten meter wind speed and direction were obtained using a propeller wind vane (R.M. Young Inc.). At the same location a tipping bucket precipitation sampler was deployed (Campbell Scientific Inc.). The four components of solar radiation, long-wave incoming (LW $\downarrow$ ) and outgoing (LW $\uparrow$ ), plus short-wave incoming ( $\mathrm{SW} \downarrow$ ) and outgoing ( $\mathrm{SW} \uparrow$ ), were measured using a Kipp and Zonen CNR1 (Campbell Scientific Inc.) at several locations in the measurement footprint at the $1.5 \mathrm{~m}$-height. UV-B (280 to $315 \mathrm{~nm}$ ) was measured near the chamber location with a UVR1-B ultraviolet pyranometer (Middleton Inc.).

Air temperature and relative humidity were measured inside the chamber and just outside the chamber at the $30 \mathrm{~cm}$-height using a CS215 temperature and humidity probe 


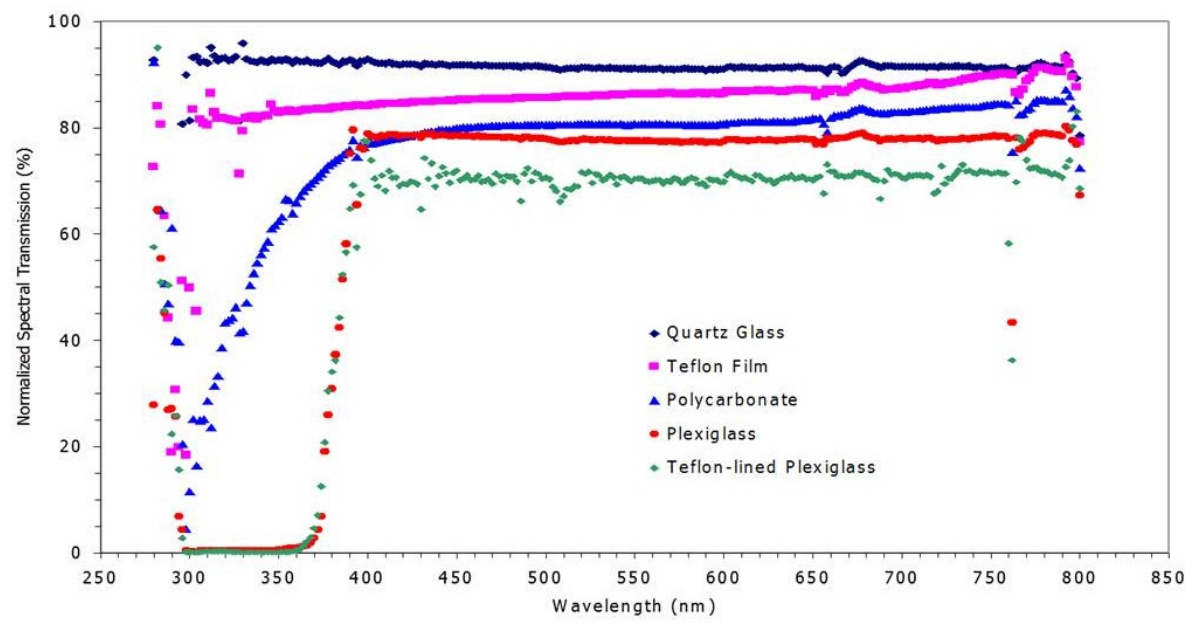

Fig. 2. Spectroradiograph measurements of materials commonly used for flux chamber construction.

(Campbell Scientific Inc.). Soil temperature was measured using $25 \mathrm{~cm}$-long, spatial-averaging thermocouples placed $2 \mathrm{~cm}$ below the soil surface within the chamber footprint and at the same depth nearby the chamber footprint. Additionally, a soil temperature profile was obtained near the chamber measurement location at the 2,5 and $10 \mathrm{~cm}$-depths, complimented by soil heat flux plates at $5 \mathrm{~cm}$-depth. Soil moisture measurements were obtained using a CS616 water content reflectometer (Campbell Scientific Inc.). Soil moisture was also obtained gravimetrically.

Data from the sensors described above were collected using Campbell Scientific Inc. data loggers.

\subsubsection{Substrate sampling and analysis}

At the end of the measurement period, for each chamber location, bulk soil samples were collected from the chamber footprint $\left(0.1 \mathrm{~m}^{2}\right)$. Substrate samples were taken from the surface interval ( 0 to $2 \mathrm{~cm}$ ) and from a deeper interval ( 5 to $10 \mathrm{~cm}$ below the surface). Samples were dried and homogenized, and particle analysis was performed using sieves. The total mercury (THg) concentration in the soil samples was determined using a Milestone DMA-80 mercury analyzer (EPA Method 7473). A set of sample duplicates were also sent to an independent laboratory, National Measurement Institute, NSW, for analysis of total mercury using acid digestion and cold vapour atomic absorption spectrophotometry (CV-AAS). Elemental determinations were also carried out on the samples using XRF to obtain mineralization profiles.

Soil samples were collected to determine soil bulk density. Soil organic and inorganic matter content was determined using the loss on ignition (LOI) method described by Nelson and Sommers (1996). Soil $\mathrm{pH}$ was determined using a 1:5 soil/water $(s / w)$ suspension on an air-dry basis, as described in Rayment and Higginson (1992).

\section{Results and discussion}

Chamber flux measurements were obtained at six locations at the Pulganbar site. Three locations were naturally enriched substrates, labelled M1 to M3, and three were background substrates (i.e. $<0.1 \mu \mathrm{g} \mathrm{g}^{-1}$ ), labelled B1 to B3. Measurements were undertaken over two periods, the first during autumn, 12 April 2011 to 19 April 2011 (DOY 102 to 109) and the second during winter, 17 June 2011 to 26 June 2011 (DOY 168 to 177). Locations M1, M2, B1 and B2 were measured during the April field campaign while M3 and B3 were measured during the June study. The results therefore span a range of substrate concentrations and climatic conditions.

The Pulganbar mine and smelter were closed in 1924 with all machinery having been removed and the mine shaft filled in. Today there is very little evidence of the old mine and smelters as the ruins are heavily overgrown with trees and grasses. In view of the potential influence of the old smelter on the flux measurements, an analysis of the chamber inlet concentrations as a function of wind direction was performed. This analysis showed no wind sector bias, thereby confirming no local influences on the flux data presented herein. Furthermore, the measurement site is located far from any anthropogenic sources on the regional scale.

Prior to starting the chamber measurements for the June study, an ambient background measurement was made over several hours during daytime at the $3 \mathrm{~m}$-level. The average background recorded was $1.22 \pm 0.03 \mathrm{ng} \mathrm{m}^{-3}$.

\subsection{Substrate characteristics}

The mercuriferous substrates were granular sandy soils with grain size fractions of approximately $60 \%$ granule (grain diameter $<2 \mathrm{~mm}), 20 \%$ sand $(63 \mu \mathrm{m}$ to $2 \mathrm{~mm})$ and $20 \%$ silt plus clay $(<63 \mu \mathrm{m})$. In contrast, the background soils were $50 \%$ silt plus clay, $30 \%$ sand and $20 \%$ granule. XRF 
Table 1. Summary of average substrate $\mathrm{THg}$ concentration, soil organic matter, bulk density and $\mathrm{pH}$.

\begin{tabular}{|c|c|c|c|c|c|c|}
\hline & $\begin{array}{l}\text { Depth } \\
(\mathrm{cm})\end{array}$ & $\begin{array}{l}\text { THg Concentration } \\
\left(\mu \mathrm{g} \mathrm{g}^{-1}\right)\end{array}$ & $\begin{array}{l}\text { Ratio of } \mathrm{THg} \text { Conc. } \\
\text { depth to surface }\end{array}$ & $\begin{array}{l}\text { SOM } \\
\text { (63 micron) }(\%)\end{array}$ & $\begin{array}{l}\text { Dry Bulk Density } \\
\left(\mathrm{g} \mathrm{cm}^{-3}\right)\end{array}$ & $\begin{array}{l}\mathrm{pH} \\
(1: 5 s / w)\end{array}$ \\
\hline \multirow[t]{2}{*}{ Site M1 } & $0-2$ & 2.3 & \multirow[t]{2}{*}{1.5} & 3.7 & & 6.4 \\
\hline & $5-10$ & 3.4 & & 3.0 & & 6.3 \\
\hline \multirow[t]{2}{*}{ Site M2 } & $0-2$ & 3.3 & \multirow[t]{4}{*}{1.5} & 5.8 & & 5.7 \\
\hline & $5-10$ & 5.0 & & 3.7 & & 5.6 \\
\hline \multirow[t]{2}{*}{ Site M3 } & $0-2$ & 0.250 & & 4.2 & 1.62 & 6.5 \\
\hline & $5-10$ & & & & & \\
\hline \multirow[t]{2}{*}{ Site B1 } & $0-2$ & 0.044 & \multirow[t]{2}{*}{1.6} & 6.2 & & 5.3 \\
\hline & $5-10$ & 0.07 & & 3.9 & & 5.3 \\
\hline \multirow[t]{2}{*}{ Site B2 } & $0-2$ & 0.065 & \multirow[t]{2}{*}{1.6} & 11.7 & & 5.3 \\
\hline & $5-10$ & 0.102 & & 5.2 & & 5.3 \\
\hline \multirow[t]{2}{*}{ Site B3 } & $0-2$ & 0.050 & \multirow[t]{2}{*}{1.7} & 9.4 & 1.46 & 5.1 \\
\hline & $5-10$ & 0.084 & & 4.2 & 1.64 & 5.2 \\
\hline
\end{tabular}

analysis showed both mercuriferous and background soils to be approximately $50 \%$ silicates with high $\mathrm{Fe}, \mathrm{Al}, \mathrm{Ag}$, and Ti content. The mercuriferous soils were also high in $\mathrm{Cu}$ and As, while the background soils were below detection limits for these elements. Table 1 summarizes the mercuriferous and background THg content measured with the DMA-80, as well as soil organic matter (SOM), bulk density and $\mathrm{pH}$. Due to instrument malfunction, soil moisture data are not available.

The THg substrate data consistently showed higher concentrations in the 5 to $10 \mathrm{~cm}$ layer than the 0 to $2 \mathrm{~cm}$ sample depth for all sites except for site M3. This was due to the small thickness of mineralized matter deposited on the surface at this location. The ratio of depth-to-surface THg concentrations is also consistent across all sites with an average ratio of 1.6 .

Background sites B1 and B3 were bare soil sites, whereas site $\mathrm{B} 2$ was a sparsely vegetated site with mostly $\mathrm{O}_{i}$ horizon leaf litter, twigs, and grass. Samples of these materials were collected and separated into two categories for analysis: (1) leaf litter and (2) grass and twigs. The samples were homogenized using a stainless steel coffee mill and analyzed using a DMA-80 (EPA method 7473). Results of this analysis showed $\mathrm{THg}$ for leaf litter as $0.041 \pm 0.001 \mu \mathrm{g} \mathrm{g}^{-1}$ and $0.044 \pm 0.005 \mu \mathrm{g} \mathrm{g}^{-1}$ for grass \& twigs. The leaf litter results compare with an $O_{i}$ horizon average leaf litter $\mathrm{THg}$ reported recently by Obrist (2012) for 12 US forests of $0.038 \mu \mathrm{g} \mathrm{g}^{-1}$, as well as that of Graydon et al. (2008) who reported an average leaf litter $\mathrm{THg}$ over 5 forest sites in Canada of $0.041 \mu \mathrm{g} \mathrm{g}^{-1}$. Lastly, it is noteworthy that Site B2 also had the highest $\mathrm{SOM}$ in the 0 to $2 \mathrm{~cm}$ soil sample, suggesting an $O$ a horizon.

Average soil $\mathrm{pH}$ for the background sites was 5.25, in contrast to that for the naturally enriched sites of 6.1. Relationships between GEM flux, soil $\mathrm{pH}$ and SOM will be discussed further in Sect. 3.3.
To enable comparison of the DMA-80 THg in soil analysis with data collected in NH studies where acid digestion and CV-ASS was used, a set of duplicate samples were sent to an independent lab for analysis by acid digestion and CV-ASS. Means of the results from the two analytical methods were compared using a standard Student's $t$ test. Testing showed the means of the two methods not to be significantly different.

\subsection{GEM flux magnitudes}

The dynamic flux chamber measurements for the six sites were calculated half-hourly and are reported here as average daytime and nighttime fluxes (demarcated by a net radiation threshold of $20 \mathrm{~W} \mathrm{~m}^{-2}$ ), as well as overall averages. These data are presented in Table 2. Also tabulated in Table 2 are average air and soil temperatures, solar and UV-B radiation. Mean day and night GEM fluxes showed both emission and deposition, ranging from a maximum emission of $174 \pm 13 \mathrm{ng} \mathrm{m}^{-2} \mathrm{~h}^{-1}$ for daytime flux over a mercuriferous substrate, to a deposition flux of $-0.33 \pm 0.05 \mathrm{ng} \mathrm{m}^{-2} \mathrm{~h}^{-1}$ over a background substrate.

Across the two study periods, overall net emission was observed over both mercuriferous and background sites. The combined overall average GEM flux over mercuriferous sites was $47.2 \pm 3 \mathrm{ng} \mathrm{m}^{-2} \mathrm{~h}^{-1}$, in contrast to the combined overall average GEM flux of $0.36 \pm 0.06 \mathrm{ng} \mathrm{m}^{-2} \mathrm{~h}^{-1}$ for all background sites. The daytime combined average flux for mercuriferous sites was $82 \pm 6 \mathrm{~nm}^{-2} \mathrm{~h}^{-1}$ with a nighttime GEM flux average of $34 \pm 3 \mathrm{ng} \mathrm{m}^{-2} \mathrm{~h}^{-1}$. The combined average GEM flux for daytime and nighttime over all background substrates were of $1.4 \pm 0.1 \mathrm{ng} \mathrm{m}^{-2} \mathrm{~h}^{-1}$ and $0.02 \pm 0.05 \mathrm{ng} \mathrm{m}^{-2} \mathrm{~h}^{-1}$, respectively. During the June study, overall deposition was observed at night at the background site (B3), with an average nighttime GEM flux of $-0.33 \pm 0.05 \mathrm{ng} \mathrm{m}^{-2} \mathrm{~h}^{-1}$. 
Table 2. Summary of GEM fluxes and environmental parameters measured over six locations at the Pulganbar site during the April and June field campaigns.

\begin{tabular}{|c|c|c|c|c|c|c|}
\hline & & $\begin{array}{l}\text { Hg Flux } \\
\left(\mathrm{ng} \mathrm{m}^{-2} \mathrm{~h}^{-1}\right)\end{array}$ & $\begin{array}{l}\text { Air Temp. } \\
\left({ }^{\circ} \mathrm{C}\right)\end{array}$ & $\begin{array}{l}\text { Soil Temp. } \\
\left({ }^{\circ} \mathrm{C}\right)\end{array}$ & $\begin{array}{l}\text { Solar } \\
\left(\mathrm{W} \mathrm{m}^{-2}\right)\end{array}$ & $\begin{array}{l}\text { UV-B } \\
\left(\mathrm{W} \mathrm{m}^{-2}\right)\end{array}$ \\
\hline \multicolumn{7}{|l|}{ April } \\
\hline \multirow[t]{3}{*}{ Site M1 } & Day & $108 \pm 15(n=12)$ & 22 & 23 & 200 & 0.39 \\
\hline & Night & $76 \pm 6(n=32)$ & 15 & 18 & & \\
\hline & Overall & $85 \pm 6$ & 17 & 19 & & \\
\hline \multirow[t]{3}{*}{ Site M2 } & Day & $174 \pm 13(n=23)$ & 21 & 20 & 148 & 0.21 \\
\hline & Night & $90 \pm 4(n=60)$ & 17 & 17 & & \\
\hline & Overall & $113 \pm 6$ & 18 & 18 & & \\
\hline \multirow[t]{3}{*}{ Site B1 } & Day & $1.1 \pm 0.1(n=21)$ & 23 & 23 & 164 & 0.2 \\
\hline & Night & $0.73 \pm 0.05(n=56)$ & 18 & 19 & & \\
\hline & Overall & $0.83 \pm 0.05$ & 19 & 20 & & \\
\hline \multirow[t]{3}{*}{ Site B2 } & Day & $0.37 \pm 0.06(n=11)$ & 26 & 22 & 156 & 0.22 \\
\hline & Night & $0.09 \pm 0.04(n=27)$ & 18 & 20 & & \\
\hline & Overall & $0.17 \pm 0.04$ & 20 & 21 & & \\
\hline \multicolumn{7}{|l|}{ June } \\
\hline \multirow[t]{3}{*}{ Site M3 } & Day & $33 \pm 3(n=49)$ & 18 & 17 & 118 & 0.13 \\
\hline & Night & $8 \pm 1(n=164)$ & 11 & 17 & & \\
\hline & Overall & $14 \pm 1$ & 13 & 17 & & \\
\hline \multirow[t]{3}{*}{ Site B3 } & Day & $2.0 \pm 0.1(n=32)$ & 18 & 25 & 107 & 0.11 \\
\hline & Night & $-0.33 \pm 0.05(n=120)$ & 9 & 17 & & \\
\hline & Overall & $0.17 \pm 0.09$ & 11 & 18 & & \\
\hline
\end{tabular}

The naturally enriched substrates flux data (i.e. M1 to M3) were obtained over a range of substrate concentrations, showing a clear relationship between flux and substrate concentration. This general relationship has been observed by others (Gustin et al., 1999a; Edwards et al., 2001; Rasmussen et al., 1998) and will be explored further in Sect. 3.4.

\subsection{Environmental correlates}

To investigate environmental correlates, data from the June study were selected, as these data offered longer continuous time series for mercuriferous and background measurement sites than the April data sets. During the June study period there was no precipitation, therefore the controlling climatic variables during this period were temperature and radiation. Figure 3 presents diel composite graphs constructed using the half-hour data obtained over four days at the mercuriferous site and four days at the background site.

Figure $3 \mathrm{a}, \mathrm{b}$ shows the diel flux cycle for the mercuriferous and backgrounds sites respectively, along with the corresponding diel composite of total incoming solar radiation and UV-B $\left(\times 10^{3}\right)$ to illustrate the relationship with these components of radiation. The modality/pattern differences seen between the mercuriferous and background sites in the composite diel flux graphs result from tree canopy shading vari- ation with solar angle. The area where the flux measurement sites were located was sparsely treed, thus the background and mercuriferous sites were located differently with respect to the canopy architecture.

It has been observed from laboratory-based studies that UV-B radiation enhances GEM flux and it is suggested that this is due to UV-B directly reducing divalent forms of mercury to elemental in the soil compartment (Choi and Holsen, 2009; Carpi et al., 2007; Moore and Carpi, 2005). Figure 3a, b shows both the mercuriferous and background GEM flux diel modality responds to, and generally better follows, total incoming solar than UV-B. This is particularly evident later in the day, where secondary peaks in the flux seen at 16:00 h at both sites are accompanied by corresponding peaks in total solar but not in UV-B. Later in the day, the intensity of UV-B radiation drops off due to solar angle and increased absorption by ozone through the longer solar path. Figure $4 \mathrm{e}, \mathrm{f}$ shows the relationship between In (GEM flux) and UV-B and total solar, respectively. The data show a weak correlation between GEM flux and both radiation signals for the background site, however a relatively stronger relationship with solar than with UV-B can be seen for the mercuriferous site. From these results, UV-B is seen to weakly influence background fluxes but not the enriched site flux. Furthermore, the stronger correlation between solar and GEM fluxes for the 

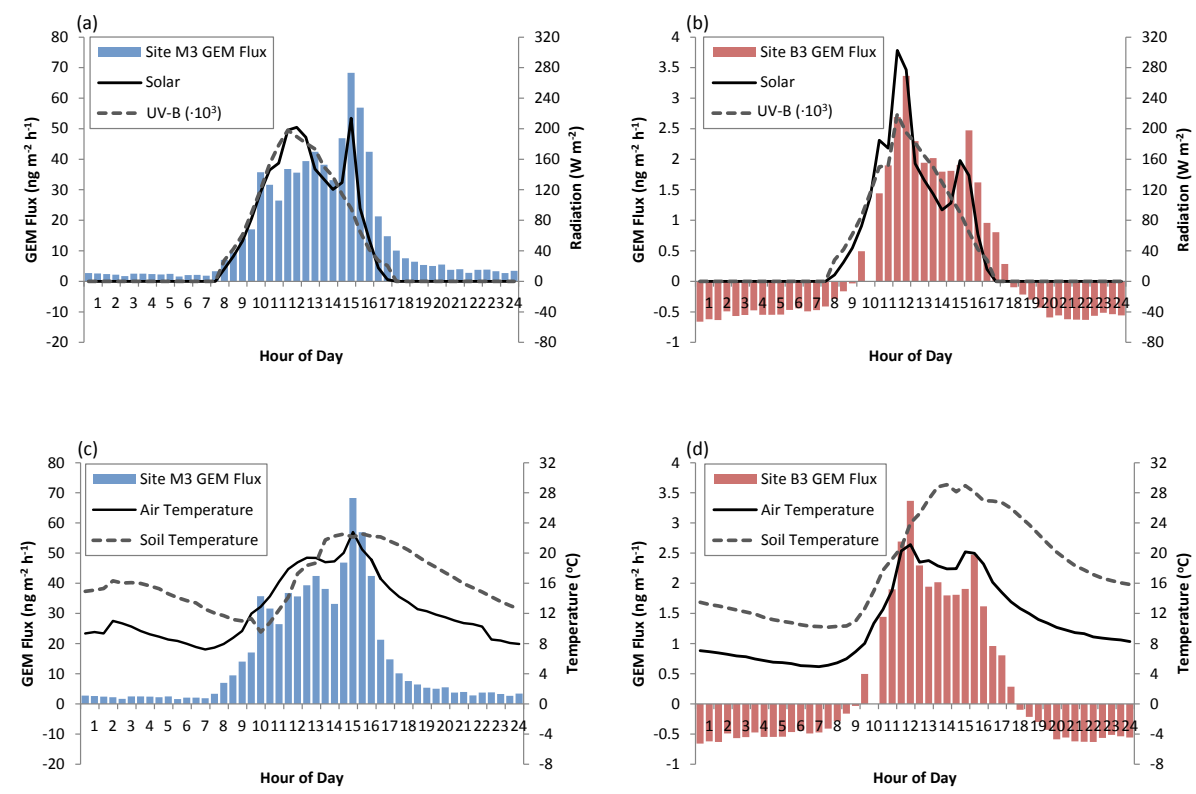

Fig. 3. Diel composite GEM flux, radiation and temperature data from June study. Top graphs compare GEM flux with radiation measurements taken over a mercuriferous (a) and background (b) site. Bottom graphs compare GEM flux with temperature measurements taken over a mercuriferous (c) and background (d) site.

enriched site suggests the latter are more temperature-driven. There is a need for more full-scale experimental data with UV-B radiation to confirm laboratory observations.

Figure 3c, d shows the same GEM diel flux data as Fig. 3a, $\mathrm{b}$, along with ambient air temperature and soil surface temperature, measured within the chamber footprint. It is evident that the correlation with chamber air temperature is much stronger than with chamber footprint soil surface temperature.

During this study, both soil surface temperature $(2 \mathrm{~cm}$ depth) and ambient air temperature were measured inside the chamber and just outside the chamber. This was done to investigate possible chamber influences on the natural temperature regime. Figure $4 a, b, c, d$ and Table 3 show the results of plotting and regressing these four temperatures with the natural logarithm of half-hourly GEM emission fluxes. The logarithm was performed as linear relationships were stronger than seen with the raw flux data. The data were further segregated into day and night fluxes. Note that, as site B3 nighttime fluxes were almost exclusively depositional, these data were excluded from this analysis. In general, it is clear from comparing Fig. 4a, b to Fig. 4c, $d$ that the GEM fluxes are significantly better correlated with air temperature than soil temperature. Comparison of the emission flux versus temperature relationships for temperatures within and outside the chamber (i.e. Fig. 4a vs. Fig. 4b and Fig. 4c vs. Fig. 4d) suggests that the chamber is not significantly influencing the flux-temperature relationship.

While soil temperature is a key correlate with respect to mercury evasion, as the soil temperature is important to the in-soil processes that supply GEM for evasion, the other processes that control this evasion are diffusion through the quasi-laminar layer near the soil surface and turbulent diffusion above that. These processes are, in addition, central to the sensible heating of the air. In this context we would expect to see a better correlation of GEM flux with air temperature than with soil temperature.

The data collected during the June study, bin averaged as seen in Fig. 3, highlight that the background site displayed emission during the day and deposition at night. Xin and Gustin (2007) and Gustin et al. (2006) suggested that air GEM concentration is an important predictor of soil $\mathrm{Hg}$ flux direction and defined an associated compensation point concept for soils. The compensation point is the ambient air concentration at which the net GEM flux between the soil and the atmosphere go to zero. Following Xin and Gustin (2007), Fig. 5 was constructed from the June background flux data set using both daytime and nighttime data. The dotted vertical line shows the ambient background measured during the June study (i.e. $1.22 \pm 0.03 \mathrm{ng} \mathrm{m}^{-3}$ ), delineating those emission fluxes that were not used for the linear regression constructed in order to determine the compensation point. A strong linear relationship is seen, giving the compensation point as $2.48 \mathrm{ng} \mathrm{m}^{-3}$. This compensation point lies within the range reported by Xin and Gustin (2007), however these data were taken during both light and dark conditions, under varying temperature and radiation regimes. These data are some of the first full-scale experimental data to demonstrate the soil compensation point concept. 

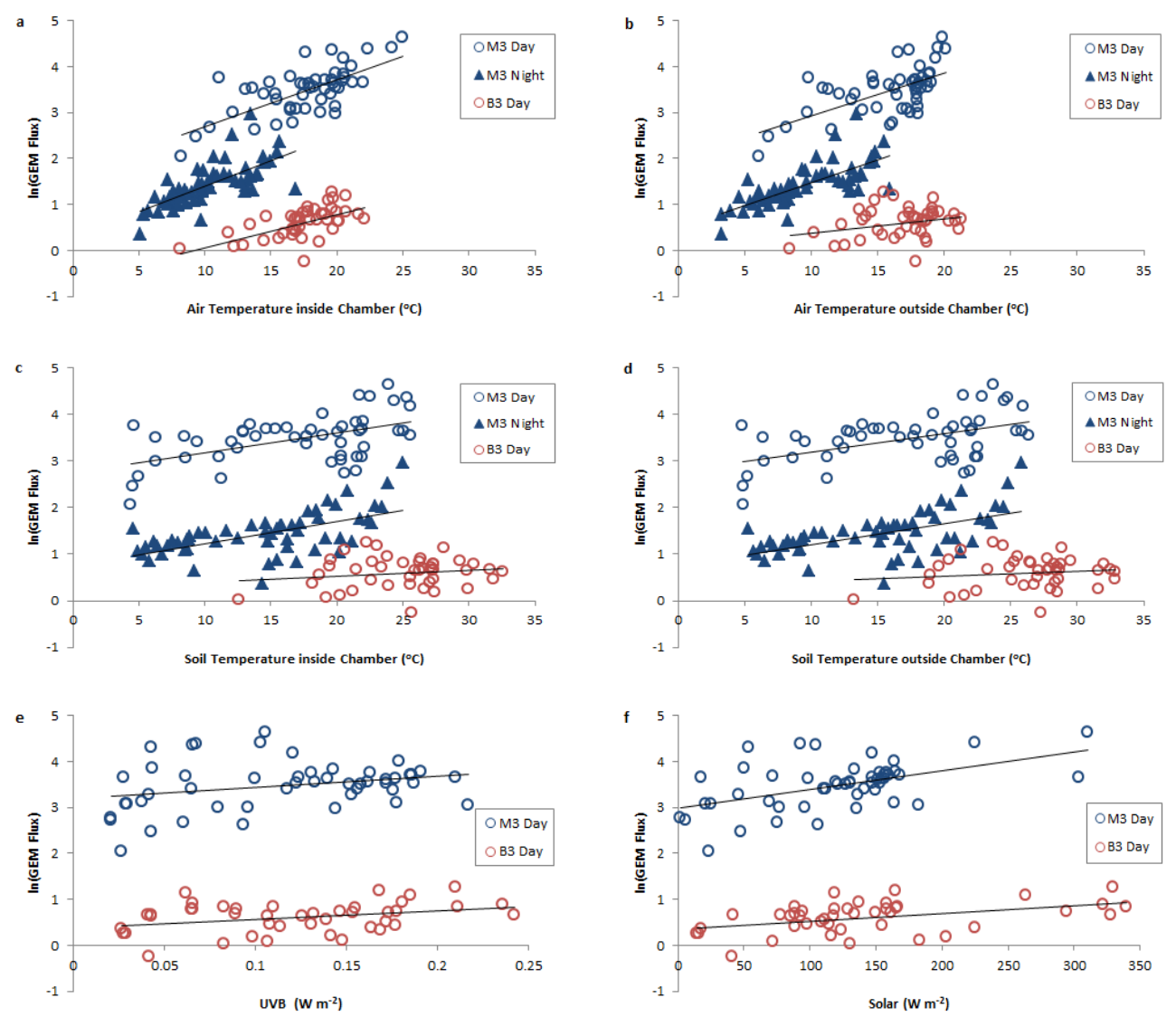

Fig. 4. Natural logarithms of GEM emission fluxes measured over sites M3 (blue) and B3 (red), compared to air temperature inside (a) and outside (b) the chamber; soil temperature inside (c) and outside (d) the chamber; and incident UVB (e) and solar (f) radiation. Circles represent measurements taken during the day (defined as net radiation $>20 \mathrm{~W} \mathrm{~m}^{-2}$ ) whilst triangles represent measurements taken at night.

Table 3. Linear correlation coefficients for relationships shown in Fig. 4.

\begin{tabular}{lllll}
\hline Site & Correlate & Slope & Intercept & $r^{2}$ \\
\hline M3 Day & Chamber Air Temp $\left({ }^{\circ} \mathrm{C}\right)$ & $0.10 \pm 0.02$ & $1.7 \pm 0.3$ & 0.48 \\
& Outside Air Temp $\left({ }^{\circ} \mathrm{C}\right)$ & $0.09 \pm 0.02$ & $2.0 \pm 0.3$ & 0.39 \\
& Chamber Soil Temp $\left({ }^{\circ} \mathrm{C}\right)$ & $0.04 \pm 0.01$ & $2.8 \pm 0.2$ & 0.27 \\
& Outside Soil Temp $\left({ }^{\circ} \mathrm{C}\right)$ & $0.04 \pm 0.01$ & $2.8 \pm 0.2$ & 0.24 \\
& UVB $\left(\mathrm{W} \mathrm{m}^{-2}\right)$ & $2 \pm 1$ & $3.2 \pm 0.2$ & 0.07 \\
& Solar $\left(\mathrm{W} \mathrm{m}^{-2}\right)$ & $0.004 \pm 0.001$ & $3.0 \pm 0.1$ & 0.26 \\
\hline \multirow{2}{*}{ M3 Night } & Chamber Air Temp $\left({ }^{\circ} \mathrm{C}\right)$ & $0.11 \pm 0.02$ & $0.3 \pm 0.2$ & 0.49 \\
& Outside Air Temp $\left({ }^{\circ} \mathrm{C}\right)$ & $0.10 \pm 0.01$ & $0.5 \pm 0.1$ & 0.53 \\
& Chamber Soil Temp $\left({ }^{\circ} \mathrm{C}\right)$ & $0.047 \pm 0.009$ & $0.8 \pm 0.1$ & 0.35 \\
& Outside Soil Temp $\left({ }^{\circ} \mathrm{C}\right)$ & $0.046 \pm 0.009$ & $0.7 \pm 0.1$ & 0.34 \\
\hline \multirow{3}{*}{ 33 Day } & Chamber Air Temp $\left({ }^{\circ} \mathrm{C}\right)$ & $0.07 \pm 0.01$ & $-0.7 \pm 0.3$ & 0.37 \\
& Outside Air Temp $\left({ }^{\circ} \mathrm{C}\right)$ & $0.03 \pm 0.02$ & $0.1 \pm 0.3$ & 0.09 \\
& Chamber Soil Temp $\left({ }^{\circ} \mathrm{C}\right)$ & $0.01 \pm 0.01$ & $0.3 \pm 0.3$ & 0.02 \\
& Outside Soil Temp $\left({ }^{\circ} \mathrm{C}\right)$ & $0.01 \pm 0.01$ & $0.3 \pm 0.3$ & 0.02 \\
& UVB $\left(\mathrm{W} \mathrm{m}{ }^{-2}\right)$ & $1.8 \pm 0.8$ & $0.4 \pm 0.1$ & 0.11 \\
& Solar $\left(\mathrm{W} \mathrm{m}{ }^{-2}\right)$ & $0.0017 \pm 0.0005$ & $0.34 \pm 0.09$ & 0.20 \\
\hline
\end{tabular}




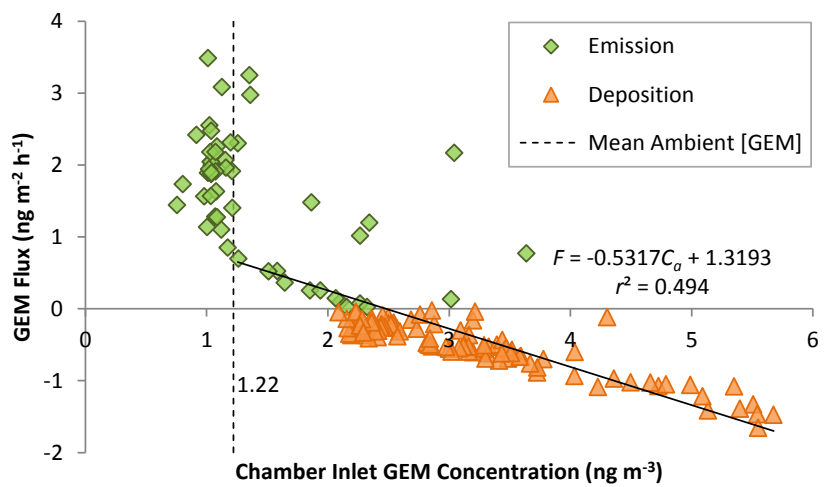

Fig. 5. GEM fluxes, and GEM concentrations at the chamber inlet, taken over Site B3 during June study. Chamber inlet GEM concentrations greater than the mean ambient taken at the beginning of the study were used to construct the linear least squares trend, where $F$ $=$ GEM flux and $C_{\mathrm{a}}=$ GEM concentration.

Soil organic matter has been suggested to influence the GEM flux from background soils (Moore and Castro, 2012; Yang et al., 2007; Grigal, 2003). While data from this study are not sufficient to fully explore this correlate, SOM does not appear to correlate with the mercuriferous site fluxes as would be expected (Mauclair et al., 2008). However, the data in Tables 1 and 2 do show a corresponding decrease in GEM flux with increasing SOM for the background sites.

The average soil $\mathrm{pH}$ for the background sites was 5.2, contrasting with the average $\mathrm{pH}$ for the mercuriferous sites of 6.1 and suggesting an increase with increasing GEM flux. This has generally been observed by others (Yang et al., 2007; Xin and Gustin, 2007). Soil pH impacts the mobility of mercury in the soil compartment. Schluter (2000) has suggested that with increasing soil $\mathrm{pH}$ there is an increased reduction of $\mathrm{Hg}^{2+}$ compounds to elemental mercury in the soil compartment.

Zhang et al. (2009) have pointed out that very limited data are available on dry deposition of GEM and Zhang et al. (2012) show GEM dry deposition to be more important than previously assumed. Sufficient deposition data to calculate dry deposition velocities were available for the June background site only. The data showed dry deposition velocities ranging from $0.00025 \mathrm{~cm} \mathrm{~s}^{-1}$ to $0.0083 \mathrm{~cm} \mathrm{~s}^{-1}$, with an average value of $0.0041 \pm 0.00018 \mathrm{~cm} \mathrm{~s}^{-1}$. These data represent bare soil, nighttime conditions for soil properties shown in Table 1 and climatic conditions in Table 2. A comparable average deposition velocity of $0.003 \pm 0.0007 \mathrm{~cm} \mathrm{~s}^{-1}$ was obtained using a dynamic flux chamber by Erickson et al. (2006) over pine forest soils.

\subsection{Comparison with Northern Hemisphere data}

In the absence of Southern Hemisphere air-surface exchange data, modelling efforts applied to SH domains have had to rely on $\mathrm{NH}$ data for emission factors, deposition rates and as- sociated empiricism. As such, natural emissions inventories for Australia have been based on indirect estimates, rather than reliable data.

Over the past decade a series of field studies over naturally enriched and background terrestrial landscapes were carried out in Canada and USA (Edwards et al., 2001, 2002, 2005; Schroeder et al., 2005; Gustin et al., 1999a, b; Lindberg et al., 1999). Data from these studies showed a strong relationship between emission flux and substrate concentration for naturally enriched sites and highlighted relationships with environmental factors such as temperature, solar radiation, precipitation and soil moisture. For background substrates, the relationship to substrate $\mathrm{THg}$ concentration is not as distinct, with air-surface exchange processes for these substrates being controlled by additional biological and chemical factors (Rasmussen et al., 2005). Figure 6 shows North American (NA) flux data plotted against substrate concentration from these studies.

These data were collected over the $\mathrm{NH}$ summer season with an overall average temperature of $14.3^{\circ} \mathrm{C}$. On the same plot we have displayed the data collected over the mercuriferous and background substrates presented herein. The overall average temperature during these measurements was $15.5^{\circ} \mathrm{C}$. The Australian mercuriferous and background data behaved in a similar manner as the NA data, with the naturally enriched substrate data showing a strong relationship between emission flux and substrate concentration. The Australian background flux data behaved similarly to the NA background flux data by not showing a correlation with substrate THg.

Two separate trend lines were purposely fitted to the NA and Australian data from mercuriferous sites with a view to illustrating differences in the average behavior of the naturally enriched data. The slopes for the two data sets are not significantly different but the intercept is displaced upwards for the Australian data. This displacement is due to an overall difference in environmental factors between the two data sets. Temperature is likely to be the principal reason for the upward shift of the Australian trend line, as the average temperature over the Australian studies (i.e. autumn/winter season) was $1.2^{\circ} \mathrm{C}$ warmer that for the NA data (i.e. summer).

Based on this result, an approximate $30 \%$ increase in mercury emissions to the atmosphere from naturally enriched sources is seen for a $1.2^{\circ} \mathrm{C}$ temperature increase. Although there are insufficient data from this study to develop a broad relationship between GEM flux, substrate THg concentration and temperature, it is clear that applying a NH relationship for substrate concentration vs. flux to Australian environs would need to take into account Australian temperature regimes. Another important implication of this result pertains to climate change. Following projections to the global mean temperature under the most modest IPCC climate change scenario, a $30 \%$ increase in mercury emissions to the atmosphere from naturally enriched sources could occur by the mid-21st century (IPCC, 2007). 


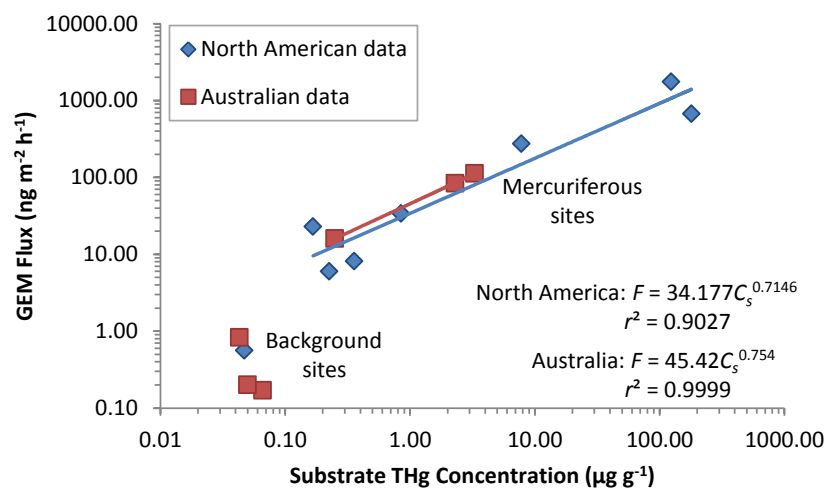

Fig. 6. Mean GEM flux and substrate THg data taken over Australian and North American mercuriferous and background sites. Linear least squares lines are fitted to mercuriferous sites only, with $F=$ GEM flux and $C_{\mathrm{s}}=$ substrate $\mathrm{THg}$ concentration.

\section{Summary and conclusion}

Prior to undertaking the GEM air-surface exchange measurements presented here, there were no direct measurements of $\mathrm{Hg}$ exchange available for Australian landscapes. GEM fluxes were obtained over both naturally enriched and background soils and over a range of climatic conditions during Australian autumn and winter periods. Large GEM emissions were observed over the naturally enriched sites compared to small net emissions from background sites, with one background site displaying both emission and deposition.

Strong correlations were observed between the GEM flux and the climatic variables temperature and radiation. The relative role of UV-B and total solar radiation was not clear, however pointed to the need for full-scale field experiments that measure UV-B and solar radiation to address this uncertainty. GEM emission from both naturally enriched and background substrates correlated strongly with temperature. The background soils with higher soil organic matter showed relatively lower fluxes to those with less soil organic matter content. Average fluxes increased with increasing soil $\mathrm{pH}$ and a compensation point for background bare soil of 2.48 was determined. The latter result is from some of the first fullscale field data to clearly demonstrate a compensation point for bare soil.

In view of the dearth of data on deposition velocities for GEM and its importance in dry deposition of mercury (Zhang et al., 2012), it was determined from the periods of deposition that the dry deposition velocities ranged from $0.00025 \mathrm{~cm} \mathrm{~s}^{-1}$ to $0.0083 \mathrm{~cm} \mathrm{~s}^{-1}$, with an average value of $0.0041 \pm 0.00018 \mathrm{~cm} \mathrm{~s}^{-1}$. These data represent bare, background soil under nighttime conditions.

Strong correlations were observed between substrate $\mathrm{THg}$ and fluxes for the mercuriferous sites but not for the background substrates. Comparison of the Australian flux substrate relationship for mercuriferous substrates with a rela- tionship derived from North American data showed good agreement with respect to slope, however the intercept was positively offset. This intercept offset was explained by the average temperature difference between the NA and Australian data. A $30 \%$ increase in emission to the atmosphere from naturally enriched substrates was shown for a $1.2^{\circ} \mathrm{C}$ temperature increase. This has interesting implications when it comes to using NA-based emission rates and empiricism to estimate Australian natural emission inventories. A further implication of this relationship is that a $1.2^{\circ} \mathrm{C}$ increase in global temperature due to climate change could also release approximately $30 \%$ more mercury from naturally enriched sources to the atmosphere.

Results from these two pilot studies confirm the need for Australian-specific data on air-surface exchange of atmospheric mercury. Characteristic and reliable data are needed that are representative of Australia's unique climatic conditions, vegetation types, land use patterns and soils, including their spatial and temporal variability. With a ratio of natural to anthropogenic sources to the atmosphere thought to be $9: 1$, Australia presents a unique opportunity to study and address uncertainties in the global biogeochemical cycle of mercury associated with land-atmosphere cycling.

Acknowledgements. Authors would like to thank Macquarie University for funding which contributed to the Australian data presented in this paper. The Canadian data presented herein was funded, by the Natural Sciences and Engineering Research Council of Canada (NSERC). Thanks are extended to Orfeo Colebatch (Science Officer at Macquarie University) for technical and field study support and to Tanya Bradley for overseeing the processing of soil samples and undertaking the XRF analysis. Thanks are also extended to Peter Nelson and Tony Morrison of the Department of Environment \& Geography, Macquarie University for their collegial support.

A Tekran 2537A, Tekran 1110, and Milestone are trademarked.

Edited by: R. Cohen

\section{References}

ABS, Australian Bureau of Statistics: Year Book Australia, http: //abs.gov.au/AUSSTATS, 1912.

BOM, Bureau of Meteorology: Australian Government, Climate of Australia, ISBN: 978064270601 0, printed by BPA print group PTY Ltd., 214 pp., 2008.

Carpi, A., Frei, A., Cocris, D., McCloskey, R., Contreras, E., and Ferguson, K.: Analytical artifacts produced by a polycarbonate chamber compared to a teflon chamber for measuring surface mercury fluxes, Anal. Bioanal. Chem., 388, 361-365, doi:10.1007/s00216-006-1111-0, 2007.

Choi, H. D. and Holsen, T. M.: Gaseous mercury fluxes from the forest floor of the Adirondacks, Environ. Pollut., 157, 592-600, doi:10.1016/j.envpol.2008.08.020, 2009.

Cope, M. E., Hibbard M. F., Lee, S., McGregor, J. L., Meyer, C. P., Morrison, A. L., and Nelson, P. F.: The transport and fate 
of Mercury in Australia: Atmospheric Transport modelling and Dispersion, Appendix 1to report RFT100/0607 to Department of Environment, Water, and Heritage and the Arts, The Centre for Australian Weather and Climate Research, 60 pp., 2009.

CWGOLD, Central West Gold, 2008 annual report, http://www. centralwestgold.com.au, 2008.

Eckley, C. S., Gustin, M., Lin, C. J., Li, X., and Miller, M. B.: The influence of dynamic chamber design and operating parameters on calculated surface-to- air mercury fluxes, Atmos. Environ., 44, 194-203, doi:10.1016/j.atmosenv.2009.10.013, 2010.

Edwards, G. C. and Howard, D. A.: Flux methods development and application to the measurement of the air-surface exchange of atmospheric mercury from natural sources over Australian ecosystems, Composition of the Atmosphere-Abstracts of the fifth CAWCR workshop, Melbourne, Australia, 15-17 November, 2011.

Edwards, G. C., Rasmussen, P. E., Schroeder, W. H., Kemp, R. J., Dias, G. M., Fitzgerald- Hubble, C. R., Wong, E. K., HalfpennyMitchell, L., and Gustin, M. S.: Sources of variability in mercury flux measurements, J. Geophys. Res.-Atmos., 106, 5421-5435, doi:10.1029/2000jd900496, 2001.

Edwards, G. C., Rasmussen, P. E., Ausma, S., Dharwarkar, G., Steffan, S., Hazlewood, P., Schroeder, W. H., and Dias, G. M.: The assessment of the evasion of mercury from a mercuriferous shale deposit using micr+ometeroloigical and dynamic chamber methods, Joint CSCE/EWRI of ASCE International Conference on Environmental Engineering, Niagara Falls Canada, 21-24 July, 2002.

Edwards, G. C., Rasmussen, P. E., Schroeder, W. H., Wallace, D. M., Halfpenny- Mitchell, L., Dias, G. M., Kemp, R. J., and Ausma, S.: Development and evaluation of a sampling system to determine gaseous mercury fluxes using an aerodynamic micrometeorological gradient method, J. Geophys. Res.-Atmos., 110, D10306, doi:10.1029/2004jd005187, 2005.

Ericksen, J. A., Gustin, M. A., Xin, M., Weisberg, P. J., and Fernandez, G. C. J.: Air-soil exchange of mercury from background soils in the United States, Sci. Total Environ., 366, 851-863, doi:10.1016/j.scitotenv.2005.08.019, 2006.

Gillis, A. and Miller, D. R.: Some potential errors in the measurement of mercury gas exchange at the soil surface using a dynamic flux chamber, Sci. Total Environ., 260, 181-189, doi:10.1016/s0048-9697(00)00562-3, 2000.

Graydon, J. A., St. Louis, V. L., Hintelmann, H., Lindberg, S. E., Sandilands, K. A., Rudd, J. W. M., Kelly, C. A., Hall, B. D., and Mowat, L. D.: Long-term wet and dry deposition of total and methyl mercury in the remote boreal ecoregion of Canada, Environ. Sci. Technol., 42, 8345-8351, doi:10.1021/es801056j, 2008.

Grigal, D. F.: Mercury sequestration in forests and peatlands: A review, J. Environ. Qual., 32, 393-405, 2003.

Gustin, M. S.: Are mercury emissions from geologic sources significant? A status report, Sci. Total Environ., 304, 153-167, doi:10.1016/s0048-9697(02)00565-x, 2003.

Gustin, M. S., Lindberg, S., Marsik, F., Casimir, A., Ebinghaus, R., Edwards, G., Hubble-Fitzgerald, C., Kemp, R., Kock, H., Leonard, T., London, J., Majewski, M., Montecinos, C., Owens, J., Pilote, M., Poissant, L., Rasmussen, P., Schaedlich, F., Schneeberger, D., Schroeder, W., Sommar, J., Turner, R., Vette, A., Wallschlaeger, D., Xiao, Z., and Zhang, H.: Nevada storms project: Measurement of mercury emissions from naturally enriched surfaces, J. Geophys. Res.-Atmos., 104, 21831-21844, doi:10.1029/1999jd900351, 1999a.

Gustin, M. S., Rasmussen, P., Edwards, G., Schroeder, W., and Kemp, J.: Application of a laboratory gas exchange chamber for assessment of in situ mercury emissions, J. Geophys. Res.Atmos., 104, 21873-21878, doi:10.1029/1999jd900344, 1999b.

Gustin, M. S., Engle, M., Ericksen, J., Lyman, S., Stamenkovic, J., and Xin, M.: Mercury exchange between the atmosphere and low mercury containing substrates, Appl. Geochem., 21, 1913-1923, doi:10.1016/j.apgeochem.2006.08.007, 2006.

Gustin, M. S., Kolker, A., and Gårdfeldt, K.: Transport and fate of mercury in the environment, Appl. Geochem., 23, 343-344, doi:10.1016/j.apgeochem.2007.12.005, 2008.

IPCC: Climate Change 2007: The Physical Science Basis. Contribution of Working Group I to the Fourth Assessment Report of the Intergovernmental Panel on Climate Change, edited by: Solomon, S., Qin, D., Manning, M., Chen, Z., Marquis, M., Averyt, K. B., Tignor, M., and Miller, H. L., Cambridge University Press, Cambridge, United Kingdom and New York, NY, USA, 2007.

Kemp, R. J.: Measurement of gaseous mercury emission from Natural sources, Ph.D. Thesis, University of Guelph, School of Engineering, Guelph, Canada, 2001.

Lindberg, S. E., Zhang, H., Gustin, M., Vette, A., Owens, J., Marsik, F., Casimir, A., Ebinghaus, R., Edwards, G. C., Fitzgerald, C., Kemp, J., Kock, H. H., London, J., Majewski, M., Poissant, L., Pilote, M., Rasmussen, P. E., Schaedlich, F., Schneeberger, D., Sommar, J., Turner, R., Wallschlaeger, D., and Xiao, Z.: Increases in mercury emissions from desert soils in response to rainfall and irrigation, J. Geophys. Res., 104, 21879-21888, 1999.

Mauclair, C., Layshock, J., and Carpi, A.: Quantifying the effect of humic matter on the emission of mercury from artificial soil surfaces, Appl. Geochem., 23, 594-601, doi:10.1016/j.apgeochem.2007.12.017, 2008.

Moore, C. and Carpi, A.: Mechanisms of the emission of mercury from soil: Role of UV radiation, J. Geophys. Res.-Atmos., 110, D24302, doi:10.1029/2004jd005567, 2005.

Moore, C. W. and Castro, M. S.: Investigation of factors affecting gaseous mercury concentrations in soils, Sci. Total Environ., 419, 136-143, doi:10.1016/j.scitotenv.2011.12.068, 2012.

Nelson, D. W. and Sommers, L. E.: Total carbon, organic carbon, and organic matter, in: Methods of Soil Analysis part 3. Chemical methods, edited by: Sparks, D. L., Page, A. L., Helmke, P. A., Loeppert, R. H., Soltanpour, P. N., Tabatabai, M. A., Johnston, C. T., and Sumner, M. E., Soil Science Society of America, Madison, Wisconsin, 961-1010, 1996.

Nelson, P. F., Peterson, C., and Morrison, A.: Atmospheric emissions of mercury - sources and chemistry, Clean Air \& Environmental Quality, 36, 48-55, 2004.

Nelson, P. F., Nguyen, H., Morrison, A. L., Malfroy, H., Cope, M. E., Hibberd, M. F., Lee, S., McGregor, J. L., and Meyer, M. C.: Mercury sources, transportation and fate in Australia, Department of Environment, Water, Heritage \& the Arts, RFT 100/0607, 2009.

NSW, New South Wales Office of Environment and Heritage (OEH): Pulganbar Smelter \& Mines Heritage Report, http:// www.heritage.nsw.gov.au, 2003. 
Pirrone, N., Hedgecock, I. M., Cinnirella, S., and Sprovieri, F.: Overview of major processes and mechanisms affecting the mercury cycle on different spatial and temporal scales, in: ERCA $9-$ From the global mercury cycle to the discoveries of Kuiper belt objects, edited by: Boutron, C., EPJ Web of Conferences, 3-33, 2010.

Rasmussen, P. E., Edwards, G. C., Kemp, J., Hubble-Fitzgerald, C., and Schroeder, W. H.: Towards and improved natural sources inventory for mercury, in: The proceedings of Metals in the Environment: An international symposium, edited by: Skeaf, J., Metallurgical Society of the Canadian Institute of Mining, Metallurgy, and Petroleum (CIM), Montreal, 73-83, 1998.

Rasmussen, P. E., Edwards, G. C., Schroeder, W. H., Ausma, S., Steffen, A., Kemp, J., Hubble-Fitzgerald, C., El Bilali, L., and Dias, G.: Chapter 7: Measurement of gaseous mercury fluxes in the terrestrial environment, in: Mercury: Sources, Measurements, Cycles and Effects. Short Course Series volume 34, Mineralogical Association of Canada, Halifax, Nova Scotia, 2005.

Rayment, G. E. and Higginson, F. R.: Australian laboratory handbook of soil and water chemical methods, Inkata Press, 1992.

Rytuba, J. J.: Mercury from mineral deposits and potential environmental impact, Environ. Geol., 43, 326-338, 2003.

Rytuba, J. J.: Geogenic and mining sources of mercury to the environment. Chapter 2, in: Mercury: Sources, Measurements, Cycles and Effects. Short Course Series volume 34, Mineralogical Association of Canada, Halifax, Nova Scotia, 2005.

Schluter, K.: Review: evaporation of mercury from soils. An integration and synthesis of current knowledge, Environ. Geol., 39, 249-271, 2000.

Schroeder, W. H., Beauchamp, S., Edwards, G., Poissant, L., Rasmussen, P., Tordon, R., Dias, G., Kemp, J., Van Heyst, B., and Banic, C. M.: Gaseous mercury emissions from natural sources in Canadian landscapes, J. Geophys. Res.-Atmos., 110, D18302, doi:10.1029/2004jd005699, 2005.
Selin, N. E.: Global biogeochemical cycling of mercury: A review, Annu. Rev. Env. Resour., 34, 43-63, doi:10.1146/annurev.environ.051308.084314, 2009.

United Nations Environment Programme Global Mercury Partnership (UNEP): Session MS18-01, 10th International Conference on Mercury as a Global Pollutant (ICMGP), 24-29 July, Halifax, Nova Scotia, 2011.

Xin, M. and Gustin, M. S.: Gaseous elemental mercury exchange with low mercury containing soils: Investigation of controlling factors, Appl. Geochem., 22, 1451-1466, doi:10.1016/j.apgeochem.2007.02.006, 2007.

Yang, Y.-K., Zhang, C., Shi, X.-J., Lin, T., and Wang, D.-Y.: Effect of organic matter and $\mathrm{pH}$ on mercury release from soils, J. Environ. Sci., 19, 1349-1354, doi:10.1016/s1001-0742(07)60220-4, 2007.

Zhang, H., Lindberg, S. E., Barnett, M. O., Vette, A. F., and Gustin, M. S.: Dynamic flux chamber measurement of gaseous mercury emission fluxes over soils. Part 1: Simulation of gaseous mercury emissions from soils using a two-resistance exchange interface model, Atmos. Environ., 36, 835-846, 2002.

Zhang, L., Wright, L. P., and Blanchard, P.: A review of current knowledge concerning dry deposition of atmospheric mercury, Atmos. Environ., 43, 5853-5864, doi:10.1016/j.atmosenv.2009.08.019, 2009.

Zhang, L., Blanchard, P., Gay, D. A., Prestbo, E. M., Risch, M. R., Johnson, D., Narayan, J., Zsolway, R., Holsen, T. M., Miller, E. K., Castro, M. S., Graydon, J. A., Louis, V. L. St., and Dalziel, J.: Estimation of speciated and total mercury dry deposition at monitoring locations in eastern and central North America, Atmos. Chem. Phys., 12, 4327-4340, doi:10.5194/acp-12-43272012, 2012. 